\title{
CARACTERIZAÇÃO DA REDE URBANA DA REGIAO FUNCIONAL DE PLANEJAMENTO NOVE DO ESTADO DO RIO GRANDE DO SUL
}

\author{
Andréia Saugo \\ Marcelle Salles Martins
}

p. $152: 176$

revista

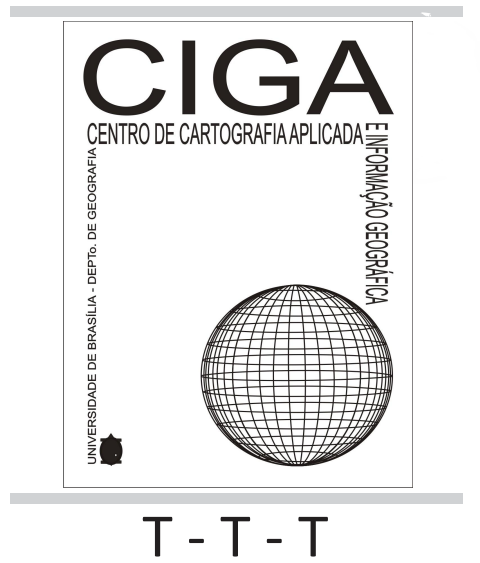

Revista Eletrônica:

Tempo - Técnica - Território,

V.3, N.1 (2012), 152:176

ISSN: 2177-4366

DOI: https://

doi.org/10.26512/

ciga.v3i1.22236
Como citar este artigo:

SAUGO. A ., Marcelle Salles martins, Andréia Saugo. CARACTERIZAÇÃO DA REDE URBANA DA REGIÃO FUNCIONAL DE PLANEJAMENTO NOVE DO ESTADO DO RIO GRANDE DO SUL

Revista Eletrônica: Tempo - Técnica - Território, v.3, n.1 (2012), p.

152:176ISSN: 2177-4366. DOI: https://doi.org/10.26512/ciga.v3i1.22236

Disponível em:

http://inseer.ibict.br/ciga/index.php/ciga/article/viewFile/288/207

Este obra está licenciado com uma Licença Crea tive Commons Atribuição-NãoComer cial 4.0 Inter nacional. 


\title{
CARACTERIZAÇÃO DA REDE URBANA DA REGIÃO FUNCIONAL DE PLANEJAMENTO NOVE DO ESTADO DO RIO GRANDE DO SUL
}

\author{
Marcele Salles Martins \\ Arquiteta e Urbanista, Mestre em Engenharia \\ Docente do Curso de Arquitetura e Urbanismo do Complexo de Ensino Superior Meridional \\ Endereço de correspondência: Rua Independência 209 / 402, Bairro Centro, Passo Fundo/RS, \\ Cep 99010-041, marcelesalles@ yahoo.com.br
}

\section{Andréia Saugo}

Arquiteta e Urbanista, Mestre em Arquitetura e Urbanismo

Docente do Curso de Arquitetura e Urbanismo da Universidade Federal da Fronteira Sul Endereço de correspondência: Rua Pedro Martinello 59, Bairro Centro, Charrua/RS,

Cep 99960-000, arqsaugo@gmail.com

\begin{abstract}
RESUMO: Nas últimas décadas, ocorreram modificações no cenário urbano das cidades brasileiras, ocasionadas principalmente pelo crescimento da urbanização, impulsionando mudanças no perfil da população urbana. Nesse sentido, este artigo apresenta um diagnóstico da rede urbana da Região Funcional de Planejamento Nove formada por 130 municípios localizados a norte do Estado do Rio Grande do Sul, no período de 1985 a 2007. A abordagem metodológica iniciou pela organização de banco de dados de indicadores, baseados em fontes oficiais. Constatou-se que a rede urbana é formada por maioria de municípios com população de até 5.000 habitantes, concentrada na zona rural. A participação econômica está baseada na atividade de serviços. De uma forma geral, os municípios apresentam problemas de saneamento básico, acesso viário, carência de atendimento médico, disparidade na distribuição de renda e elevadas taxas de analfabetismo.
\end{abstract}

Palavras-chave: Rede urbana. Diagnóstico municipal e regional. Região funcional de planejamento nove. Estado do Rio Grande do Sul. Políticas públicas.

ABSTRACT: In recent decades, changes occurred in the urban landscape of Brazilian cities, caused mainly by the growth of urbanization, driving changes in the profile of the urban population. Accordingly, this article presents a diagnosis of the urban network of Functional Planning Region Nine formed by 130 municipalities located in the north of Rio Grande do Sul, in the period 1985 to 2007. The methodological approach initiated by the organization of the database of indicators, Revista Eletrônica: Tempo - Técnica - Território, V.3, N.1 (2012), 152:176 ISSN: 2177-4366 
based on official sources. It was found that the urban network is formed by a majority of municipalities with population up to 5,000 inhabitants, concentrated in rural areas. The economic participation is based on service activity. In general, cities have problems of sanitation, road access, lack of medical care, disparities in the distribution of income and high rates of illiteracy.

Key-words: Urban network. Municipal and regional diagnosis. Planning Functional Region Nine. State Rio Grande do Sul. Public politics.

RESUMEN: En las últimas décadas, se produjeron cambios en el entorno urbano de las ciudades brasileñas, principalmente causados por la creciente urbanización, que impulsan los cambios en el perfil de la población urbana. Por lo tanto, este trabajo presenta un análisis de la red urbana de la Región de Planificación Funcional Nueve formado por 130 municipios ubicados al norte de Río Grande do Sul, en el período comprendido entre 1985 y 2007. El enfoque metodológico iniciado por la organización de base de datos de indicadores, basados en fuentes oficiales. Se encontró que la red urbana está formada por una mayoría de los municipios con población hasta 5.000 habitantes, concentrados en las zonas rurales. La participación se basa en la actividad económica de los servicios. En general, los municipios tienen problemas de saneamiento, caminos de acceso, falta de atención médica, la disparidad en la distribución del ingreso y altas tasas de analfabetismo.

Palabras clave: Red Urbana. Diagnóstico municipal y regional. Región de planificación functional nueve. Estado de Río Grande do Sul. Políticas públicas.

\section{INTRODUÇÃO}

Nas últimas décadas o crescimento da urbanização gerou modificações no cenário urbano das cidades, contribuindo para a ocorrência de mudanças no perfil da população urbana, bem como nos fluxos de troca entre os centros urbanos, decorrentes da intensificação das inter-relações entre os mercados internos e externos. A identificação dessas mudanças subsidia o conhecimento do processo de formação da rede urbana, além de auxiliar na determinação das características econômicas e territoriais, em âmbito regional, dos municípios que a compõe.

Este trabalho apresenta um diagnóstico da rede urbana da região funcional de planejamento nove do Estado do Rio Grande do Sul - RF9, formada por 130 municípios localizados a norte, integrantes de seis Conselhos Regionais de Desenvolvimento. A abordagem da rede urbana RF9 permitiu estabelecer diferenciações entre os municípios, baseadas no número de habitantes, nos indicadores econômicos e na função ou funções que os municípios desempenham, seja na atividade 
industrial, agropecuária ou prestação de serviços.

O estudo do diagnóstico da rede urbana além de contribuir para a elaboração de um banco de dados para a região, possibilita a identificação da situação em que se encontram os municípios, tanto a nível socioeconômico quanto ambiental, auxiliando no entendimento das desigualdades regionais. Essa investigação contribui para a definição de políticas públicas de investimentos e ações que visem o desenvolvimento econômico, social e ambiental dos municípios, aumentando seu nível hierárquico e competitivo e, consequentemente, sua posição no cenário regional.

\section{FORMAÇÃO TERRITORIAL DO RIO GRANDE DO SUL}

A ocupação do território do Rio Grande do Sul iniciou-se a partir do século XVII com a chegada dos jesuítas, que tinham a finalidade principal de catequizar os índios. As reduções jesuíticas, fundadas a partir de 1626, foram os primeiros núcleos estáveis no espaço rio-grandense (BARROS, 1992). Os Sete Povos das Missões se tornaram centros econômicos importantes, dedicando-se à produção de erva-mate, à extração de couro e atividades criatórias.

No século XVIII, a colonização açoriana intensificou o povoamento na faixa litorânea e ao longo do Rio Jacuí, originando propriedades rurais, com predominância do cultivo de trigo, caracterizando a base socioeconômica do Estado, além da pecuária-criação e a charqueada.

No decorrer do século XIX o Rio Grande do Sul foi influenciado pelo processo de assentamento da imigração européia, incentivado pelo governo brasileiro, a fim de povoar as áreas de mata do planalto norte rio-grandense e da serra geral. De acordo com Moreira (2000), os alemães começaram a chegar em 1824. Eles colonizaram a parte inferior da encosta do planalto norte riograndense, sobretudo os vales dos rios Caí, dos Sinos, Pardo e Taquari. Posteriormente, a imigração italiana se instalou na região nordeste do Estado.

A ocupação territorial das regiões das Missões, do Alto-Uruguai e do Planalto Médio foram concomitantes à ocupação da encosta inferior do Planalto pelos colonos alemães. Nestas regiões as propriedades eram vendidas a militares, tropeiros e criadores que deram origem as atuais cidades de Cruz Alta, Palmeira das Missões e Passo Fundo.

A ocupação e a urbanização do Estado, no século XX, toma novos rumos decorrentes da modificação da economia gaúcha, dividindo o Estado em dois momentos: até 1950 e pós-1950 (BARROS, 1992). Nesse primeiro momento, a base agrícola sofre com as consequências do uso intensivo do solo. Paralelamente, há a formação de minifúndios, reduzindo a unidade produtiva e contribuindo com a migração rural/rural. Tal fato provoca uma intensiva busca por novas terras, localizadas bem ao norte do Estado. Portanto, com a migração ocorre o surgimento de novos pólos urbanos, resultando em uma rede urbana formada por pequenos núcleos muito próximos. 
No segundo momento, pós-1950, intensifica-se a saída do homem do campo, em virtude da implantação da mecanização na agricultura, acelerando-se a migração rural/urbana e ocasionando um acréscimo populacional, principalmente, nos centros urbanos industriais.

A trajetória histórica de ocupação do território rio-grandense reflete as diferenças de distribuição da população e de desempenho econômico, sendo no sul, predominante a atividade extensiva das grandes propriedades e a baixa densidade demográfica. Enquanto que, no norte, a estrutura fundiária se encontra, predominantemente, constituída por pequenas e médias propriedades rurais, resultando em maior densidade demográfica.

\subsection{Processo de Regionalização e os Conselhos Regionais de Desenvolvimento}

O Rio Grande do Sul passou por processos de regionalização, nas décadas de 1970 e 1980, na tentativa de homogeneizar uma divisão regional que pudesse ser adotada pelos diversos órgãos setoriais do governo estadual.

No início da década de 1990, retomam-se os diálogos a respeito das estratégias a serem adotadas para possibilitar a inserção da participação da comunidade regional na formulação de propostas orçamentárias com vistas ao desenvolvimento regional, possibilitando contemplar as diferentes regiões do Estado. Neste contexto propõe-se a criação dos Conselhos Regionais de Desenvolvimento no âmbito da descentralização política, econômica e almejando a integração regional.

Segundo Bandeira (2000) "os Conselhos Regionais de Desenvolvimento (COREDEs) foram criados com a finalidade de suprir a falta de instâncias de articulação regional no Estado”. A formação dos Conselhos respeitou a autonomia das comunidades locais na escolha do COREDE ao qual seria integrante, mas de acordo com o autor, um dos critérios de escolha que deveria ser observado pelas comunidades era a preservação da continuidade territorial.

Os Conselhos Regionais de Desenvolvimento foram instituídos oficialmente pela Lei Estadual $\mathrm{N}^{\mathrm{o}} 10.283$ de 17 de outubro de 1994, e têm por objetivo a promoção do desenvolvimento regional, harmônico e sustentável, através da integração dos recursos e das ações de governo na região, visando à melhoria da qualidade de vida da população, à distribuição eqüitativa da riqueza produzida, ao estímulo à permanência do homem em sua região e à preservação e recuperação do meio ambiente (RIO GRANDE DO SUL, 1994).

Com a criação dos COREDEs a divisão regional do Estado inicia-se composta por 20 regiões. Ao longo de sua instituição, essa divisão inicial passou por desmembramentos, configurando a divisão regional atual do Estado em 28 Conselhos Regionais de Desenvolvimento. 
Com a participação dos COREDEs no processo de consulta popular, constituindo-se como "fórum organizador" das demandas regionais, os mesmos adquiriram maior relevância como mencionam as autoras Jardim e Barcellos (2005) e vêm sendo utilizados como recorte regional em estudos que visam subsidiar a formulação do planejamento estadual.

\section{REDE URBANA}

As abordagens iniciais sobre os estudos relativos à rede urbana surgem no século XVI, com o capitalismo. Mas adquirem expressão no período compreendido entre 1920 e 1955, no qual proposições teóricas e metodológicas se estabelecem, sendo foco tanto em países desenvolvidos quanto em subdesenvolvidos. Estes estudos envolvem fenômenos como a urbanização, a dinâmica urbano-rural, além do desenvolvimento regional.

O conceito de rede é abordado por diferentes perspectivas de análise. Para Castells (1999) a rede é um conjunto de nós interconectados e o nó é um ponto no qual uma curva se entrecorta.

Fonseca e O`Neill (2001) conceituam rede como sendo um entrelaçamento de fios formando um tecido, uma malha. Os fios correspondem as vias de ligação que proporcionam o entrelaçamento que são os pontos ou nós. As malhas seriam o contínuo do tecido que agregam os fios e os nós. Especificamente, nos estudos de redes urbanas, os nós vinculam-se aos centros que funcionalmente se articulam via fios, que são estradas de ferro e de rodagem, rios, por onde ocorrem os fluxos; o conjunto articulado desses centros constitui uma malha.

Para Rambo e Casarotto (2008) a rede é entendida como sendo elementos fundamentais para o desencadeamento de processos de desenvolvimento territorial, tanto de redes territorializantes quanto desterritorializantes. Nesse sentido, Haesbaert (2006) expõe que as redes possuem efeito concomitantemente territorializador e desterritorializador, onde os fluxos que circulam pela rede tenham um efeito que ora pode ser de sustentação, mais interno ou construtor de territórios, ora de desestruturação, mais, externo ou desarticulador de territórios.

A definição adotada pelo artigo é a proposta por Corrêa (2006, p. 16), que entende a rede urbana como "o conjunto de centros urbanos funcionalmente articulados entre si”.

O estudo das redes urbanas considera as organizações hierárquicas e tipológicas das cidades que as compõem, sendo que diferem entre si. A diferenciação está ligada à origem, ao tamanho e às funções. Considerando a origem, há vários tipos de cidades, umas originárias de missões religiosas, outras de entrepostos comerciais e, ainda, núcleos urbanos criados por empresas industriais.

As relações entre as diferentes funções permitem estabelecer fluxos entre as cidades e sua área de influência, os quais possuem variações quanto à periodicidade e à intensidade em que ocorrem, podendo ser mercadorias, pessoas, informações ou capital. E, por meio desses fluxos, se 
constitui a diferenciação hierárquica entre as cidades, baseadas na oferta de bens e serviços, aliada às especializações funcionais que geram complementaridade entre elas.

Relacionado, ainda, com a diferenciação dos centros urbanos pode-se mencionar, conforme Corrêa (2006, p. 27), que "a rede urbana é um reflexo, na realidade, dos efeitos acumulados da prática de diferentes agentes sociais, sobretudo as grandes corporações multifuncionais e multilocalizadas que, efetivamente, introduzem, tanto na cidade como no campo, atividades que geram diferenciações".

O estudo atual das redes, segundo Santos (2002, p. 263) “supõe a descrição do que a constitui, um estudo estatístico das quantidades e das qualidades técnicas mas, também, a avaliação das relações que os elementos da rede mantêm com a presente vida social, em todos os seus aspectos, isto é, essa qualidade de servir como suporte corpóreo do cotidiano".

\section{HIERARQUIA URBANA}

A hierarquia dos núcleos urbanos constitui um dos ângulos para se entender a configuração da rede urbana, iniciando com o interesse em compreender a natureza da diferenciação das cidades, acentuada pelo capitalismo, o qual parte de um mercado consumidor, no qual a oferta de produtos e de serviços se expande e se estabelece de forma desigual pelo território, ocasionando a formação da hierarquia das cidades.

As teorias e as proposições relativas aos estudos da hierarquia urbana datam do século XVIII, mas a principal concepção que baseia estudos pertinentes a esse tema é a teoria das localidades centrais formulada por Christaller, em 1933. Na tentativa desse geógrafo alemão compreender a forma de organização das cidades e as redes de cidades, desenvolveu um conceito geral de centralidade, como sendo uma região de influência e polarização, baseado no fluxo de bens e serviços ofertados pelo local central (grandes, médias e pequenas cidades).

A centralidade é proporcional ao conjunto de funções centrais que um núcleo exerce: quanto maior a centralidade, maior a importância do lugar, maior a região de influência, tanto maior a população externa atendida.

A hierarquização das cidades pode ser expressa por um escalonamento de funções centrais, as quais estão diretamente relacionadas à oferta de bens e serviços, identificados por Corrêa (2003, p. 23) nos seguintes tipos de centros: metrópole regional, a qual oferece a totalidade de funções centrais; capital regional, não possui um nível complexo se comparado com a primeira; centro subregional, oferta níveis intermediários de complexidade; centros da zona, apresentam níveis inferiores ao centro sub-regional; e o centro local, oferece apenas os bens e serviços de consumo frequente. 
A hierarquização da rede urbana brasileira, proposta nos estudos do Instituto de Pesquisa Econômica Aplicada - IPEA (2002, p. 38), apresenta embasamento teórico nas proposições Christallerianas, e ainda define um conjunto de funções centrais que possibilitam a construção da estruturação funcional das cidades. Para tanto, foram consideradas funções de baixa e de média a elevada complexidade, dando origem ao Projeto Regiões de Influência das Cidades - REGIC.

Os resultados obtidos no projeto REGIC representam as interações espaciais entre as cidades brasileiras, assim como suas respectivas áreas de influência, sendo possível a apresentação de níveis de centralidade (máximo, muito forte, forte, forte para médio, médio, médio para fraco, fraco e muito fraco), o número de centros correspondentes em cada nível, vinculado a um padrão de cidade.

\section{METODOLOGIA}

A pesquisa está estruturada nas etapas demonstradas na Figura a seguir.

\begin{tabular}{|c|}
\hline $\begin{array}{c}\text { Elaboração de banco } \\
\text { de dados de } \\
\text { indicadores }\end{array}$ \\
\hline
\end{tabular}

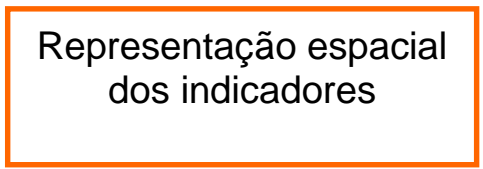

Localização da área objeto de estudo

Caracterização geral da área objeto de estudo

Figura 01: Estrutura da pesquisa.

\section{ELABORAÇÃo DE BANCO DE DAdOS DE INDICADORES Físico- TERRITORIAIS, SOCIOECONÔMICOS, EDUCACIONAIS, DEMOGRÁFICOS E DE INFRAESTRUTURA}

Os dados que formam o banco de dados foram obtidos de fontes secundárias a partir de consultas em 2007 e 2008 no Instituto Brasileiro de Geografia e Estatística (IBGE), na Fundação de Economia e Estatística Siegfried Emanuel Heuser (FEE), no Atlas Socioeconômico do Rio Grande do Sul, na Secretaria de Planejamento e Gestão do Estado do Rio Grande do Sul (SEPLAG), no Atlas do Desenvolvimento Humano no Brasil, na Fundação Estadual de Proteção Ambiental Henrique Luiz Roessler - RS (FEPAM), no Departamento Autônomo de Estradas de Rodagem (DAER) e no Instituto de Pesquisa Econômica Aplicada (IPEA).

Os dados foram coletados de bases referenciais de períodos compreendidos entre 1985 e 2007, sendo sistematizados em uma planilha eletrônica e organizados por blocos de indicadores e ano. A seguir estão expressos os indicadores obtidos, bem como os anos correspondentes:

\subsection{Indicadores Físico-Territoriais}


Este item engloba dados da área territorial dos municípios, sua data de criação e a bacia hidrográfica que faz parte. A área territorial possibilita verificar a dimensão territorial do município, relacionando-a com a densidade demográfica e com o percentual territorial pertencente a cada município perante o COREDE do qual faz parte. Os dados são relativos ao ano de 2006.

No item referente à data de criação dos municípios os dados foram distribuídos em quatro faixas (de 1857 a 1900; de 1901 a 1950; de 1951 a 1987 e de 1988 a 1996) para permitir a verificação do quantitativo de municípios que foram emancipados após a Constituição de 1988.

\subsection{Indicadores Demográficos}

Os indicadores demográficos englobam a apresentação do quantitativo da população total, urbana e rural dos municípios componentes da RF9, a densidade demográfica, a taxa de urbanização e a expectativa de vida ao nascer da população.

Nesta pesquisa, o bloco população foi distribuído em cinco faixas (até 5.000 hab; de 5.001 a 20.000 hab; de 20.001 a 50.000 hab; de 50.001 a 100.000 hab; de 100.000 a 500.000 hab), objetivando verificar o comportamento populacional na região de estudo.

As informações populacionais foram baseadas nos anos 1985, 1990, 1996, 2000, 2006 e na contagem populacional do ano de 2007. Quanto à densidade demográfica foi obtida no ano de 2006, referente à divisão da área territorial pela população total no ano mencionado. Já no quesito da taxa de urbanização foi distribuída em quatro faixas: 0 a 25,0; de 25,01 a 50,0; de 50,01 a 75,0 e de 75,01 a 100,0. Os dados foram baseados nos anos 1985, 1990, 2000 e 2006 e permitem inferir sobre a ocupação da zona urbana dos municípios.

A expectativa de vida ao nascer refere-se aos anos de 1991 e 2000, configurando um dos fatores auxiliares na avaliação da qualidade de vida da sua população.

\subsection{Indicadores de Saúde}

Os indicadores de saúde compreendem a taxa de mortalidade infantil, o quantitativo de estabelecimentos de saúde e os leitos disponíveis.

A taxa de mortalidade infantil foi distribuída basicamente em quatro faixas: 0,0 a 0,5; de 0,6 a 0,15; de 0,16 a 2,0; de 2,1 a 3,0, podendo apresentar um número maior de faixas, no caso, de algum município ultrapassar o índice 3,0, tendo-se os dados observados nos anos 1996, 2000 e 2006. Este indicador que mensura quantas crianças menores de um ano, dentre as que nasceram vivas, morreram em determinado tempo, período e local, permite a comparação da qualidade de vida de uma região com outra. 
Os dados referentes ao número de estabelecimentos de saúde e leitos disponíveis foram baseados no ano de 2007, sendo utilizados para a verificação da oferta de serviços e de atendimento.

\subsection{Indicadores Educacionais}

Neste bloco de indicadores foram considerados o quantitativo de estabelecimentos de Ensino Fundamental e Médio, bem como o número de alunos atendidos nestes níveis de ensino no ano de 2005. Os estabelecimentos de ensino, considerados nesta pesquisa, totalizam as escolas municipais, estaduais e particulares dos municípios da RF9 e o quantitativo de alunos refere-se à matrícula inicial no respectivo nível de ensino.

Engloba este bloco a oferta de Instituições de Ensino Superior (IES) nos municípios, no ano de 2008, assim como verifica a média de acesso e a de frequência de pessoas ao Ensino Superior, na faixa etária dos 18 aos 24 anos, considerados os dados do ano 2000.

Para verificar a qualidade de educação oferecida pelos municípios utilizou-se o Índice de Desenvolvimento da Educação Básica (Ideb). O Ideb é um indicador que reúne dois conceitos importantes para a qualidade da educação: fluxo escolar e médias de desempenho nas avaliações.

A taxa de analfabetismo é outro indicador utilizado neste item. A taxa foi distribuída em quatro faixas percentuais: 0,0 a 10,0; 10,1 a 15,0; de 15,1 a 20,0; de 20,1 a 100,0, os dados foram baseados no ano de 2000. Relaciona-se ao percentual de pessoas analfabetas - incapazes de escrever um bilhete simples - de 15 anos ou mais de idade (faixa etária na qual, por lei, a escolaridade seria obrigatória) (FEE, 2008).

\subsection{Indicadores Econômicos}

Esse bloco de indicadores se baseia nos valores do Produto Interno Bruto - PIB, PIB Per capita, Valor Adicionado Bruto - VAB nas atividades agropecuária, indústria e serviços.

Os valores do PIB e dos setores do VAB foram baseados nos anos 1996, 2000, 2004, 2005 e 2006, expressos em Reais (R\$ mil). O PIB aborda dados de 1996, 2000 e 2005, em Reais (R\$ mil).

\subsection{Indicadores Sociais}

No bloco, dos indicadores sociais se apresentam o Índice Desenvolvimento Socioeconômico (IDESE) e os seus blocos temáticos: Domicílio e Saneamento, Educação, Renda e Saúde; o Índice de Desenvolvimento Humano Municipal (IDH-M) e o Índice de Gini.

O Índice de Desenvolvimento Socioeconômico - IDESE foi criado pela Fundação de Economia e Estatística Siegfried Emanuel Heuser para acompanhar e mensurar o nível de desenvolvimento do Estado do Rio Grande do Sul. É um índice sintético, inspirado no IDH (Índice 
de Desenvolvimento Humano), que tem por objetivo medir o grau de desenvolvimento dos municípios do Rio Grande do Sul.

Os municípios podem ser classificados pelo IDESE em três níveis: baixo desenvolvimento (índices até 0,499), médio desenvolvimento (entre 0,500 e 0,799) e alto desenvolvimento (maiores que 0,800$)$ (FEE, 2008).

\subsection{Indicadores de Infraestrutura}

Os indicadores de infraestrutura incluem a verificação das rodovias que possibilitam o acesso às sedes municipais, a forma de abastecimento de água e o esgotamento sanitário, o destino do lixo e a fonte de geração e distribuição de energia.

Para a verificação das rodovias que possibilitam o acesso às sedes municipais dos municípios componentes da RF9 foi utilizado o mapa rodoviário do Estado do Rio Grande do Sul, disponibilizado pelo Departamento Autônomo de Estradas de Rodagem - DAER, com as seguintes convenções: acesso pavimentado, trecho implantado, trecho em pavimentação e acesso sem pavimentação. Os dados foram baseados no ano de 2007.

A forma de abastecimento de água foi indicada por rede geral (quando o domicílio estava ligado à rede geral de abastecimento) ou por poço ou nascente na propriedade (quando o domicílio era servido por água de poço ou nascente localizado no terreno ou na propriedade em que estava construído; ou quando o domicílio era servido de água de reservatório (ou caixa), abastecido com água das chuvas, por carro-pipa ou, ainda, por poço ou nascente localizados fora do terreno ou da propriedade na qual estava construído), nos domicílios particulares permanentes, sendo os dados referidos aos anos de 1991 e 2000 (FEE, 2008).

Os dados do saneamento se referem ao número de domicílios particulares permanentes por tipo de esgotamento sanitário do banheiro, nos anos 1991 e 2000, segundo classificação da FEE (2008): rede geral de esgoto ou pluvial; fossa rudimentar; fossa séptica; vala; rio, lago ou mar.

Com relação ao destino do lixo, nos anos 1991 e 2000, os dados se referem ao número de domicílios particulares permanentes por forma de disposição: coletado, enterrado na propriedade, jogado ou queimado na propriedade, conforme dados da FEE (2008).

Entende-se por domicílio particular permanente a definição utilizada pela FEE (2008) “quando construído para servir exclusivamente à habitação e, na data de referência, tinha a finalidade de servir de moradia a uma ou mais pessoas".

Com relação a fonte de geração de energia, os dados correspondem ao ano de 2008 e quanto aos dados que se referem à fonte distribuidora de energia foram baseados no ano de 2005. 


\subsection{Nível de Hierarquia}

O estudo das Regiões de Influência das Cidades - REGIC classificou os municípios brasileiros a partir da definição de um conjunto de funções que possibilitassem classificar os centros urbanos pelo seu nível de centralidade, vinculados à oferta de bens e serviços disponíveis. Os níveis de centralidade propostos para o enquadramento das cidades brasileiras, em 1993, foram: máximo, muito forte, forte, forte para médio, médio, médio para fraco, fraco e muito fraco (IPEA, 2000).

A pesquisa utilizou como base a publicação do REGIC, cuja classificação foi estabelecida um valor de 8 até 1, para cada nível, a fim de possibilitar a confecção da representação espacial deste indicador na área objeto de estudo: 8 - máximo; 7 - muito forte; 6 - forte; 5 - forte para médio; 4 médio; 3 - médio para fraco; 2 - fraco e 1 - muito fraco.

\subsection{Representação Espacial dos Indicadores na Área de Estudo}

As informações que compõem o banco de dados foram sistematizadas em uma planilha eletrônica e incorporadas ao software Arc Gis, permitindo a confecção de mapas temáticos, os quais expressam as representações espaciais relativas aos indicadores demográficos (população total e taxa de urbanização), taxa de mortalidade infantil, taxa de analfabetismo, índice de desenvolvimento humano municipal, nível de hierarquia e data de criação dos municípios da RF9.

\section{APRESENTAÇÃO E ANÁLISE DOS RESULTADOS}

\subsection{Localização da Região Funcional de Planejamento Nove}

A Região Funcional de Planejamento Nove (RF9) do Estado do Rio Grande do Sul, representada na Figura 02, localiza-se ao norte do Estado do Rio Grande do Sul. É composta por 130 municípios (2008), os quais se encontram distribuídos em seis Conselhos Regionais de Desenvolvimento - COREDEs: Alto da Serra do Botucaraí, Médio Alto Uruguai, Nordeste, Norte, Produção e Rio da Várzea.

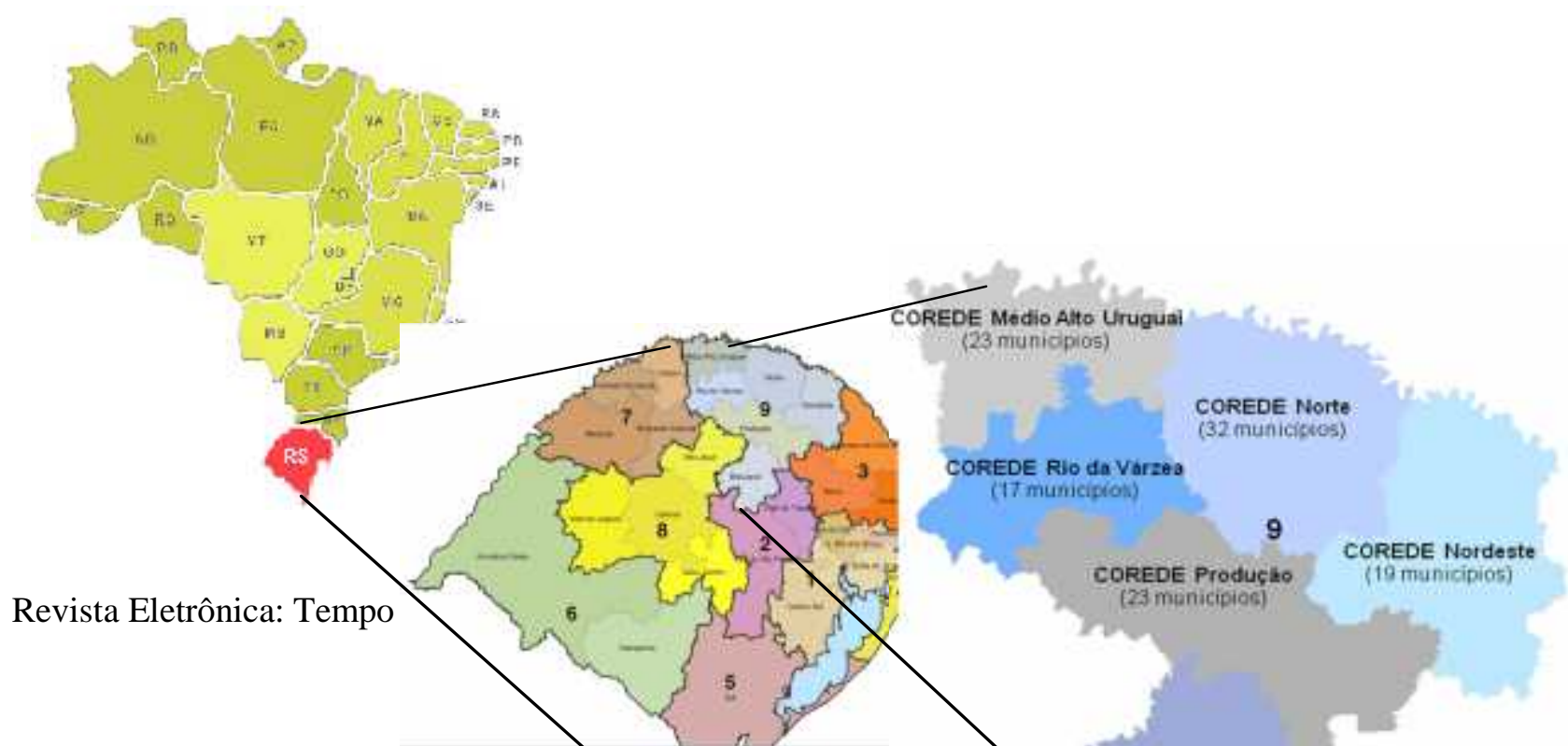


Figura 02: Localização do Estado do Rio Grande do Sul e da RF9.

Fonte: Adaptado da Secretaria de Planejamento e Gestão do Estado do Rio Grande do Sul, 2007.

O Quadro 01 apresenta os municípios que da RF9 e os seus respectivos COREDES.

Quadro 01: Municípios que compõem a RF9 e respectivos COREDEs.

Fonte: Governo do Estado do Rio Grande do Sul, 2004.

\begin{tabular}{|c|c|}
\hline COREDE & MUNICÍPIOS \\
\hline $\begin{array}{l}\text { Alto da Serra do } \\
\text { Botucaraí }\end{array}$ & $\begin{array}{l}\text { Alto Alegre, Barros Cassal, Campos Borges, Espumoso, Fontoura Xavier, } \\
\text { Gramado Xavier, Ibirapuitã, Itapuca, Jacuizinho, Lagoão, Mormaço, Nicolau } \\
\text { Vergueiro, São José do Herval, Soledade, Tio Hugo, Victor Graeff. }\end{array}$ \\
\hline $\begin{array}{l}\text { Médio Alto } \\
\text { Uruguai }\end{array}$ & $\begin{array}{l}\text { Alpestre, Ametista do Sul, Caiçara, Cristal do Sul, Dois Irmãos das Missões, } \\
\text { Erval Seco, Frederico Westphalen, Gramado dos Loureiros, Iraí, Jaboticaba, } \\
\text { Nonoai, Novo Tiradentes, Palmitinho, Pinhal, Pinheirinho do Vale, Planalto, Rio } \\
\text { dos Índios, Rodeio Bonito, Seberi, Taquaruçu do Sul, Trindade do Sul, Vicente } \\
\text { Dutra, Vista Alegre. }\end{array}$ \\
\hline Nordeste & $\begin{array}{l}\text { Água Santa, Barracão, Cacique Doble, Capão Bonito do Sul, Caseiros, Ibiaçá, } \\
\text { Ibiraiaras, Lagoa Vermelha, Machadinho, Maximiliano de Almeida, Paim Filho, } \\
\text { Sananduva, Santa Cecília do Sul, Santo Expedito do Sul, São João da Urtiga, } \\
\text { São José do Ouro, Tapejara, Tupanci do Sul, Vila Lângaro. }\end{array}$ \\
\hline Norte & $\begin{array}{l}\text { Aratiba, Áurea, Barão do Cotegipe, Barra do Rio Azul, Benjamin Constant do } \\
\text { Sul, Campinas do Sul, Carlos Gomes, Centenário, Charrua, Cruzaltense, Entre } \\
\text { Rios do Sul, Erebango, Erechim, Erval Grande, Estação, Faxinalzinho, Floriano } \\
\text { Peixoto, Gaurama, Getúlio Vargas, Ipiranga do Sul, Itatiba do Sul, Jacutinga, } \\
\text { Marcelino Ramos, Mariano Moro, Paulo Bento, Ponte Preta, Quatro Irmãos, São } \\
\text { Valentim, Sertão, Severiano de Almeida, Três Arroios, Viadutos. }\end{array}$ \\
\hline Produção & $\begin{array}{l}\text { Almirante Tamandaré do Sul, Camargo, Carazinho, Casca, Chapada, Ciríaco, } \\
\text { Coqueiros do Sul, Coxilha, David Canabarro, Ernestina, Gentil, Marau, Mato } \\
\text { Castelhano, Muliterno, Nova Alvorada, Nova Boa Vista, Passo Fundo, Pontão, } \\
\text { Santo Antônio do Palma, Santo Antônio do Planalto, São Domingos do Sul, } \\
\text { Vanini, Vila Maria. }\end{array}$ \\
\hline Rio da Várzea & $\begin{array}{l}\text { Barra Funda, Boa Vista das Missões, Cerro Grande, Constantina, Engenho } \\
\text { Velho, Lajeado do Bugre, Liberato Salzano, Novo Barreiro, Novo Xingu, } \\
\text { Palmeira das Missões, Ronda Alta, Rondinha, Sagrada Família, São José das } \\
\text { Missões, São Pedro das Missões, Sarandi, Três Palmeiras. }\end{array}$ \\
\hline
\end{tabular}

\subsection{Caracterização da RF 9 - Indicadores Físico-Territoriais}

A RF9 possui área territorial total de $33.502,5 \mathrm{Km}^{2}$ (2006), equivalente a $12 \%$ do território rio-grandense. Os municípios possuem áreas territoriais na faixa dos $60 \mathrm{Km}^{2}$ à $1.415,7 \mathrm{Km}^{2}$.

O Estado do Rio Grande do Sul está dividido em três regiões hidrográficas: a Bacia do Guaíba, a Bacia do Uruguai e a Bacia Litorânea e possui vinte e três bacias hidrográficas. A RF9 está inserida nas regiões hidrográficas da Bacia do Uruguai e da Bacia do Guaíba. Na região da Revista Eletrônica: Tempo - Técnica - Território, V.3, N.1 (2012), 152:176 ISSN: 2177-4366 
Bacia do Uruguai, verifica-se a presença das seguintes bacias hidrográficas na área objeto de estudo: Bacia do Rio Ijuí, Bacia dos Rios Turvo/Santa Rosa/Santo Cristo, Bacia Rio da Várzea, Bacia do Rio Passo Fundo, Bacia dos Rios Apuaê/Inhandava. Na região da Bacia do Guaíba, fazem parte as seguintes bacias: Bacia do Alto Jacuí, Bacia do Rio Pardo e Bacia do Rio Taquari-Antas.

A RF9 é formada por municípios jovens, pois $58 \%$ dos municípios que compõem esta região foram criados no período 1988-1996, fato explicado pelas mudanças na Constituição Brasileira, o que provocou uma onda emancipatória em todo o país (RANGEL et. al, 1998).

O município mais antigo desta região é Passo Fundo (1857) e os mais recentes foram criados no ano de 1996: Almirante Tamandaré do Sul, Capão Bonito do Sul, Cruzaltense, Jacuizinho, Novo Xingu, Paulo Bento, Quatro Irmãos, Santa Cecília do Sul, São Pedro das Missões e Tio Hugo.

\subsection{Indicadores Demográficos}

A área de estudo abriga uma população de 1.064.985 habitantes (IBGE, 2007), o que corresponde a aproximadamente $10 \%$ da população estadual, apresentando uma densidade demográfica bruta de $32 \mathrm{hab} / \mathrm{Km}^{2}$ (2006).

A população total se concentrava na faixa de 5.001 a 10.000 habitantes, nos anos de 1985 e 1990. Dos 55 municípios existentes no ano de 1985, 36\% possuíam população nesta faixa, bem como 37\% dos 83 municípios existentes no ano de 1990. Este cenário foi modificado a partir do ano de 1996, no qual os percentuais passaram a se concentrar na faixa de até 5.000 habitantes, dos 116 municípios, $53 \%$ ocupavam esta faixa.

No ano de 2000, eram 123 municípios existentes na RF9, permanecendo a concentração da população total na faixa dos municípios até 5.000 habitantes. Nos anos seguintes de análise 2006 e 2007 (130 municípios existentes), 63\% da população total concentravam-se na faixa de até 5.000 habitantes. E os percentuais das faixas populacionais dos dois últimos anos se mantiveram iguais.

A Tabela 1 apresenta a quantidade e o percentual correspondente de municípios por faixas de habitantes e nos diversos anos analisados.

Tabela 1: Quantidade de municípios correspondentes às faixas por habitantes.

\begin{tabular}{|c|c|c|c|c|c|c|c|c|c|c|c|c|}
\hline POPULAÇÃO & \multicolumn{2}{|c|}{1985} & \multicolumn{2}{|c|}{1990} & \multicolumn{2}{|c|}{1996} & \multicolumn{2}{|c|}{2000} & \multicolumn{2}{|c|}{2006} & \multicolumn{2}{|c|}{2007} \\
\hline $0-5000$ & 3 & $5,5 \%$ & 23 & $28 \%$ & 61 & $53 \%$ & 68 & $57 \%$ & 82 & $63 \%$ & 82 & $63 \%$ \\
\hline $5001-10000$ & 20 & $36 \%$ & 31 & $37 \%$ & 33 & $28 \%$ & 31 & $26 \%$ & 30 & $23 \%$ & 30 & $23 \%$ \\
\hline $10001-20000$ & 19 & $35 \%$ & 19 & $23 \%$ & 14 & $12 \%$ & 13 & $11 \%$ & 9 & $7 \%$ & 9 & $7 \%$ \\
\hline $20001-50000$ & 9 & $16 \%$ & 6 & $7 \%$ & 5 & $4 \%$ & 5 & $4 \%$ & 6 & $4,7 \%$ & 6 & $4,7 \%$ \\
\hline $50000-100000$ & 3 & $5,5 \%$ & 3 & $4 \%$ & 2 & $2 \%$ & 2 & $2 \%$ & 2 & $1,5 \%$ & 2 & $1,5 \%$ \\
\hline $100001-200000$ & 1 & $2 \%$ & 1 & $1 \%$ & 1 & $1 \%$ & 1 & $1 \%$ & 1 & $0,8 \%$ & 1 & $0,8 \%$ \\
\hline
\end{tabular}

Como pode ser observado na tabela acima, a RF9 possui em torno de $84 \%$ dos municípios com menos de 10.000 habitantes, de 1996 a 2007, sendo que em torno de 60\% destes possuem até 
5.000 habitantes. Havendo oscilações de perdas populacionais nas faixas de 10.001 a 20.000 e de 20.001 a 50.000 habitantes, devido aos movimentos migratórios internos que tiveram origem na região norte com destino a região nordeste do Estado, como expõem Alonso e Amaral (2005) e Jardim e Barcellos (2005).

Os municípios que possuem população total de até 5.000 habitantes, no ano de 2007, considerando a contagem populacional, são: Água Santa, Almirante Tamandaré do Sul, Alto Alegre, Áurea, Barra do Rio Azul, Barra Funda, Benjamin Constant do Sul, Boa Vista das Missões, Cacique Doble, Camargo, Campos Borges, Capão Bonito do Sul, Carlos Gomes, Caseiros, Cerro Grande, Charrua, Ciriaco, Coqueiros do Sul, Coxilha, Cristal do Sul, Cruzaltense, David Canabarro, Dois Irmãos das Missões, Engenho Velho, Entre Rios do Sul, Erebango, Ernestina, Faxinalzinho, Floriano Peixoto, Gentil, Gramado dos Loureiros, Gramado Xavier, Ibiaçá, Ibirapuitã, Ipiranga do Sul, Itapuca, Itatiba do Sul, Jaboticaba, Jacuizinho, Jacutinga, Lajeado do Bugre, Mariano Moro, Mato Castelhano, Mormaço, Muliterno, Nicolau Vergueiro, Nova Alvorada, Nova Boa Vista, Novo Barreiro, Novo Tiradentes, Novo Xingu, Paim Filho, Paulo Bento, Pinhal, Pinheirinho do Vale, Pontão, Ponte Preta, Quatro Irmãos, Rio dos Índios, Sagrada Família, Santa Cecília do Sul, Santo Antonio do Palma, Santo Antônio do Planalto, Santo Expedito do Sul, São Domingos do Sul, São João da Urtiga, São José das Missões, São José do Herval, São Pedro das Missões, São Valentim, Severiano de Almeida, Taquaruçu do Sul, Tio Hugo, Três Arroios, Três Palmeiras, Tupanci do Sul, Vanini, Victor Graeff, Vila Lângaro, Vila Maria e Vista Alegre.

Considerando o período de 2000 a 2007, 73\% dos municípios da RF9 perderam população. Acredita-se que houve uma migração para as cidades que possuem maior oferta de emprego. A esse respeito, Jardim e Barcellos (2005) afirmam que há um deslocamento significativo populacional para os COREDEs: Vale do Rio dos Sinos, Serra e Metropolitano do Delta do Jacuí. Provavelmente, esse resultado seja "em função do dinamismo do parque industrial e o do aumento da concentração de comércio e serviços". Dentre os municípios que obtiveram os maiores percentuais de crescimento populacional estão os municípios de Passo Fundo e Marau, ambos pertencentes ao COREDE Produção.

No período analisado, houve um aumento na concentração da população urbana nas cidades, fato ocorrido após o ano de 1990, como pode se observar na Tabela 2. Este crescimento está concentrado nos municípios com mais de 50.000 habitantes, fato observado também na faixa de 20.001 a 50.000 habitantes.

Tabela 2: Percentagem da população urbana e rural total da RF9 nos anos analisados.

\begin{tabular}{llllll}
\hline POPULAÇÃO TOTAL & $\mathbf{1 9 8 5}$ & $\mathbf{1 9 9 0}$ & $\mathbf{1 9 9 6}$ & $\mathbf{2 0 0 0}$ & $\mathbf{2 0 0 6}$ \\
\hline URBANA & $47 \%$ & $52 \%$ & $59 \%$ & $64 \%$ & $68 \%$ \\
RURAL & $53 \%$ & $48 \%$ & $41 \%$ & $36 \%$ & $32 \%$ \\
\hline
\end{tabular}


Os municípios com população na faixa de 10.001 a 20.000 habitantes, nas décadas de 1980 e 1990, apresentavam a concentração populacional na zona rural, modificando o cenário no século XXI, que passou a concentrar a população na zona urbana, como demonstra a Tabela 3. Situação semelhante ocorreu com os municípios na faixa de 5.001 a 10.000 habitantes, que até o ano de 2000, possuíam a maior concentração populacional na zona rural.

Nota-se que RF9, desde o ano de 1996, concentra a maioria da população total dos municípios na faixa até 5.000 habitantes na zona rural.

Tabela 3: Quantidade de municípios na zona urbana e rural por faixa de habitantes.

\begin{tabular}{l|cc|cc|cc|cc|cc}
\hline \multicolumn{1}{c|}{ POPULAÇÃO } & \multicolumn{2}{c|}{1985} & \multicolumn{2}{c|}{1990} & \multicolumn{2}{c|}{1996} & \multicolumn{2}{c|}{2000} & \multicolumn{2}{c}{2006} \\
& Urbana & Rural & Urbana & Rural & Urbana & Rural & Urbana & Rural & Urbana & Rural \\
\hline $0-5000$ & 0 & 3 & 2 & 21 & 2 & 59 & 7 & 61 & 10 & 72 \\
$5001-10000$ & 0 & 20 & 1 & 30 & 3 & 30 & 7 & 24 & 16 & 14 \\
$10001-20000$ & 0 & 19 & 3 & 16 & 6 & 8 & 7 & 6 & 7 & 2 \\
$20001-50000$ & 3 & 6 & 5 & 1 & 5 & 0 & 5 & 0 & 6 & 0 \\
$50000-100000$ & 2 & 1 & 3 & 0 & 2 & 0 & 2 & 0 & 2 & 0 \\
$100001-200000$ & 1 & 0 & 1 & 0 & 1 & 0 & 1 & 0 & 1 & 0 \\
TOTAL MUNICÍPIOS & $\mathbf{6}$ & $\mathbf{4 9}$ & $\mathbf{1 5}$ & $\mathbf{6 8}$ & $\mathbf{1 9}$ & $\mathbf{9 7}$ & $\mathbf{2 9}$ & $\mathbf{9 1}$ & $\mathbf{4 2}$ & $\mathbf{8 8}$ \\
\hline
\end{tabular}

Os municípios da RF9, no ano de 1985, não possuíam uma taxa de urbanização expressiva. A maioria dos municípios apresentava menos de $25 \%$ de sua população em domicílios urbanos. A taxa de urbanização predominante manteve-se na faixa dos 25,1 a 50,0\%, de 1990 a 2006, como expressam as representações espaciais das Figuras 03 e 04 . Nos anos de 2000 e 2006, observou-se um crescimento na taxa de urbanização dos municípios que estavam na faixa de 50,1 a 75,0\%, sendo que a quantidade de municípios com essa faixa percentual passou de $14 \%$ (2000) para $27 \%$ em 2006. Já as taxas de urbanização na faixa de 75,1 a 100,0\% permaneceram $10 \%$, nos dois últimos anos analisados.

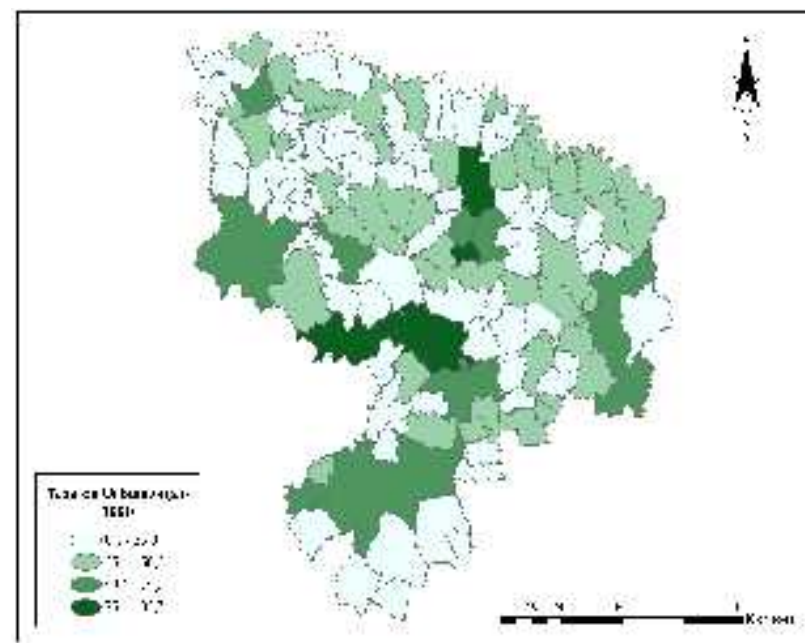

Figura 03: Representação espacial da taxa de urbanização da RF9 no ano de 1990.

Fonte: Elaborado pela autora.

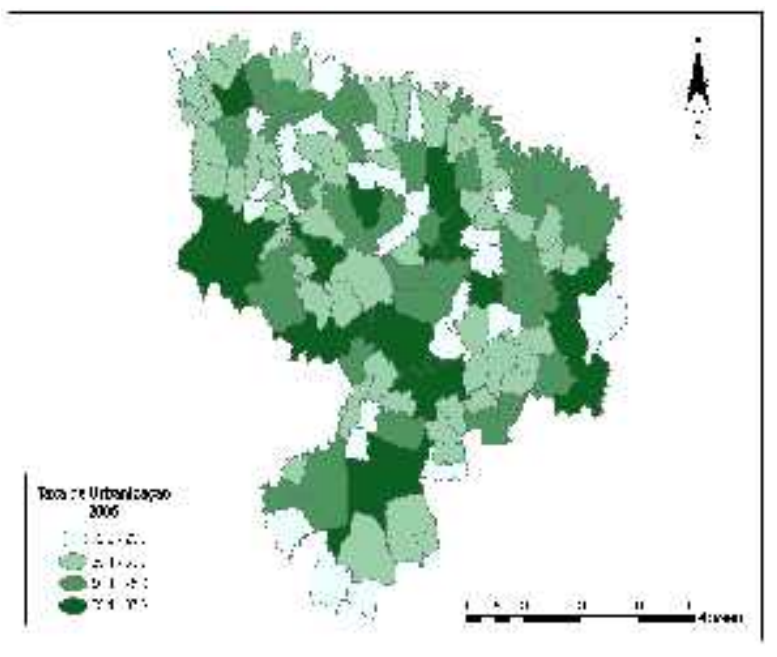

Figura 04: Representação espacial da taxa de urbanização da RF9 no ano de 2006.

Fonte: Elaborado pela autora. 
Com relação à expectativa de vida ao nascer, a RF9 possuía uma média de 63 anos, em 1991, passando para 66 anos, no ano de 2000, permanecendo abaixo da expectativa de vida dos gaúchos que era 72,05 anos (2000).

\subsection{Indicadores de Saúde}

A RF9 apresentava uma distribuição concentrada na faixa de 0,0 a $0,5 \%$ da taxa de mortalidade infantil nos anos analisados.

No ano de 1996, os municípios de Carazinho, Erechim e Passo Fundo apresentaram taxas superiores às estaduais que eram de 3,2 por mil nascidos vivos. Na RF9, os municípios de Carazinho, Erechim, Machadinho, Passo Fundo e São Domingos do Sul apresentaram taxas superiores as estaduais, em 2000, que era de 3,31 por mil nascidos vivos.

No ano de 2006, cerca de $95 \%$ dos municípios apresentaram taxas inferiores às estaduais, que eram de 4,22 por 1000 nascidos vivos. Os municípios de Carazinho, Casca, Estação, Itatiba, Passo Fundo e Vila Maria apresentaram taxas superiores às estaduais neste ano.

Na RF9, 48\% dos municípios não possuem hospitais. No ano de 2007, a região concentrava $23 \%$ dos estabelecimentos de saúde do Estado e 16\% dos leitos disponíveis. Na maioria dos municípios, há a presença de postos de saúde, ambulatórios e muitos municípios possuem o Programa Saúde da Família (PSF) promovido pelo governo municipal.

O município de Passo Fundo se destaca como centro de atendimento médico especializado de saúde, uma vez que possui o maior número de estabelecimentos e leitos disponíveis da RF9. Portanto, absorve boa parte do atendimento médico e hospitalar da população que reside nos municípios que compõem a região objeto de estudo.

\subsection{Indicadores Educacionais}

A RF9 no ano de 2005, contava com 1.221 estabelecimentos de Ensino Fundamental, 184 estabelecimentos de Ensino Médio e 14 estabelecimentos de Ensino Superior. Algumas Instituições de Ensino Superior (IES) possuíam extensões nos municípios de Carazinho, Casca, Frederico Westphalen, Lagoa Vermelha, Palmeira das Missões, Sarandi e Soledade. Além das IES presenciais, a RF9 contava com unidades de ensino à distância que foram instaladas nos municípios de Camargo, Constantina, Jacuizinho, Seberi, Tapejara e Tio Hugo. Este fato contribuiu para o aumento do acesso ao Ensino Superior, bem como do número de pessoas que estão frequentando o Ensino Superior, na faixa etária dos 18 aos 24 anos.

O Índice de Desenvolvimento da Educação Básica (Ideb) na RF9 aumentou a média dos níveis de ensino, tanto nos anos iniciais quanto nos anos finais do Ensino Fundamental, ficando acima dos totais nacionais, no período analisado, como demonstra o Quadro 02. A partir dos dados 
dos anos 2005 e 2007 se observa também que a região melhorou na qualidade da educação oferecida à comunidade escolar.

Quadro 02: Média do Ideb da RF9 e do Brasil, nos anos de 2005 e 2007.

Fonte: Inep, 2008.

\begin{tabular}{|l|r|r|r|r|}
\hline \multirow{4}{*}{} & \multicolumn{4}{|c|}{ ENSINO FUNDAME NTAL } \\
\cline { 2 - 5 } & \multicolumn{2}{|c|}{ ANOS INICIAIS } & \multicolumn{2}{c|}{ ANOS FINAIS } \\
\cline { 2 - 5 } & $\mathbf{2 0 0 5}$ & $\mathbf{2 0 0 7}$ & $\mathbf{2 0 0 5}$ & $\mathbf{2 0 0 7}$ \\
\hline BRASIL & 3,8 & 4,2 & 3,5 & 3,8 \\
\hline RF9 & 4,2 & 4,6 & 3,9 & 4,1 \\
\hline
\end{tabular}

A taxa de analfabetismo da área objeto de estudo ficou concentrada na faixa de 0,0 - 10,0\%, porém, dos municípios que estão nesta faixa apenas $17 \%$ possuem índices abaixo da média estadual que era 6,7, em 2000. Os municípios que apresentaram os índices inferiores ao Estado são: Almirante Tamandaré do Sul, Capão Bonito do Sul, Carazinho, Carlos Gomes, Casca, Centenário, Chapada, Cruzaltense, Erechim, Estação, Gaurama, Getúlio Vargas, Ibiraiaras, Ipiranga do Sul, Jacuizinho, Jacutinga, Marau, Nova Boa Vista, Novo Xingu, Passo Fundo, Paulo Bento, Quatro Irmãos, Santa Cecília do Sul, Santo Antônio do Planalto, São Pedro das Missões, Severiano de Almeida, Tapejara, Tio Hugo, Três Arroios, Victor Graeff. E os municípios que apresentaram taxas acima de 20,01 são: Fontoura Xavier, Lagoão, Lajeado do Bugre e São José do Herval.

\subsection{Indicadores Econômicos}

A evolução do PIB total da RF9 obteve aumento do ano de 1996 a 2004, apresentando queda em 2005, voltando a aumentar no ano de 2006, apresentando um valor total de R $\$ 13.223 .593,00$, equivalente a 8,43\% do PIB total estadual. A queda do PIB no ano de 2005 pode estar ligada à queda nas exportações dos produtos básicos, afetados pela estiagem que comprometeu importantes produtos exportáveis do Estado, segundo Haffner (2006). Os valores do PIB total da RF9 encontram-se no Gráfico 01.

Gráfico 01: Evolução do PIB total da RF9.

Fonte: Elaboração própria a partir dos dados da Fundação Economia e Estatística (FEE, 2008).

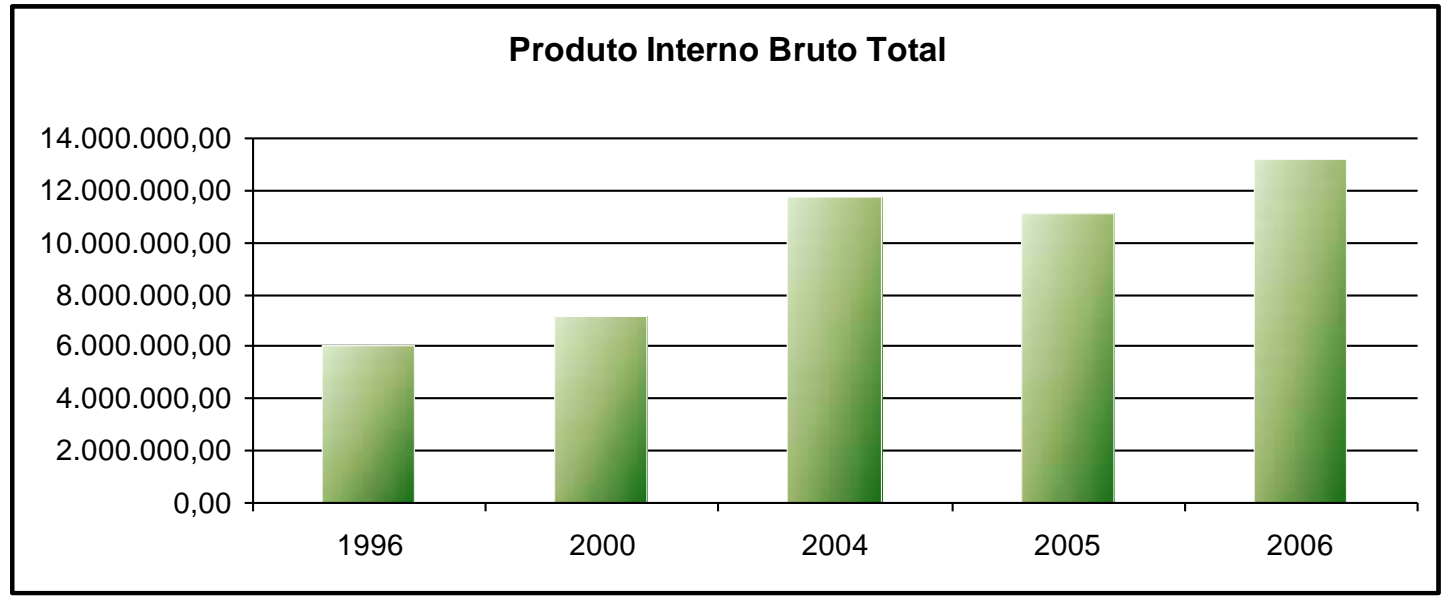


A região oscilou posições em nível estadual em relação aos percentuais do PIB total da RF9. Em 1996, o PIB total da RF9 era equivalente a 9,5\% do PIB total estadual, passou para 8,4\% em 2000. Em 2004, correspondia a 8,5\%, diminuindo no ano seguinte, apresentando um percentual de $7,7 \%$ do PIB total estadual.

O PIB per capita demonstrou crescimento na RF9, fato aliado ao bom desempenho econômico e ao pequeno crescimento populacional do período, os valores totais passaram de $\mathrm{R} \$ 6.776,91 \mathrm{em}$ 2000, para R\$ 10.429,08 no ano de 2005, e no ano de 2006, apresentaram um PIB per capita total de $\mathrm{R} \$ 12.413,22$.

A estrutura produtiva da RF9 se apresenta pautada no setor de serviços, cujos valores do VAB total desta atividade obtiveram aumento no período analisado, conforme demonstra o Gráfico 02. Entretanto a atividade industrial foi o setor que obteve maior ascensão nos anos analisados, principalmente, do ano de 2000 para 2005, que passou de $\mathrm{R} \$ 1.785 .286,00$ para $\mathrm{R} \$ 2.391 .029,00$, em virtude da instalação de indústrias nestes últimos anos nesta região.

Gráfico 02: VAB total nas atividades agropecuária, industrial e de serviços da RF9.

Fonte: Elaboração própria a partir dos dados da Fundação Economia e Estatística (FEE, 2008).

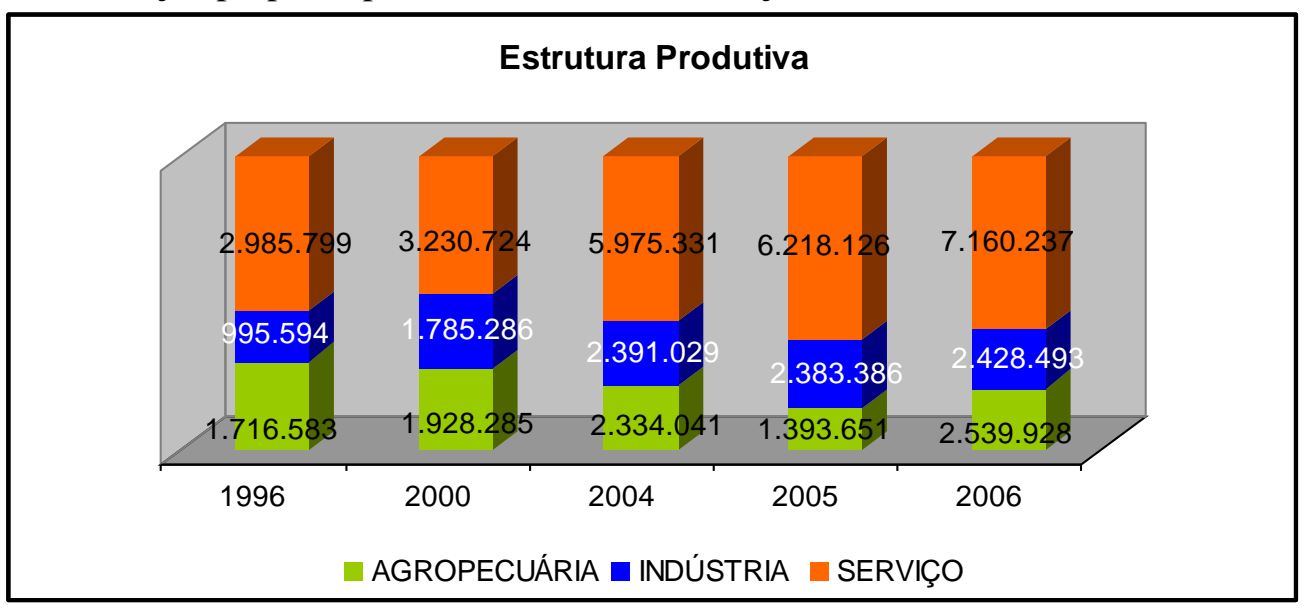

O setor agropecuário sofreu oscilações no período analisado apesar do crescimento verificado entre os anos de 1996 a 2004 e de se constituir a base econômica de muitos municípios da região norte, conforme aborda Alonso (2003). Este setor apresentou um decréscimo no ano de 2005, fator que se pode atribuir às perdas na safra de 2004/2005, em virtude o Estado ter sofrido, no início do ano de 2005, uma estiagem prolongada que afetou diretamente a produção de grãos, problema que foi associado à queda de preços de diversas commodities agrícolas e também à restrição de crédito de ICMS (HAFFNER, 2006). O VAB total da atividade agropecuária da RF9 apresentou aumento no próximo ano analisado, passando de $\mathrm{R} \$ 1.393 .651,00 \mathrm{em} 2005$ para $\mathrm{R} \$ 2.539 .928,00 \mathrm{em} 2006$.

\subsection{Indicadores Sociais}

Na RF9, o Índice de Desenvolvimento Socioeconômico (IDESE) permaneceu com índice Revista Eletrônica: Tempo - Técnica - Território, V.3, N.1 (2012), 152:176 ISSN: 2177-4366 
médio de desenvolvimento (0,50 a 0,79), nos anos analisados, conforme demonstra o Gráfico 03 . Os municípios de Erechim e Sarandi ficaram com alto desenvolvimento socioeconômico (acima de 0,80), no ano de 2004, superando o índice estadual de 0,76.

Gráfico 03: Índice de Desenvolvimento Socioeconômico

Fonte: Fundação Economia e Estatística (FEE, 2008).

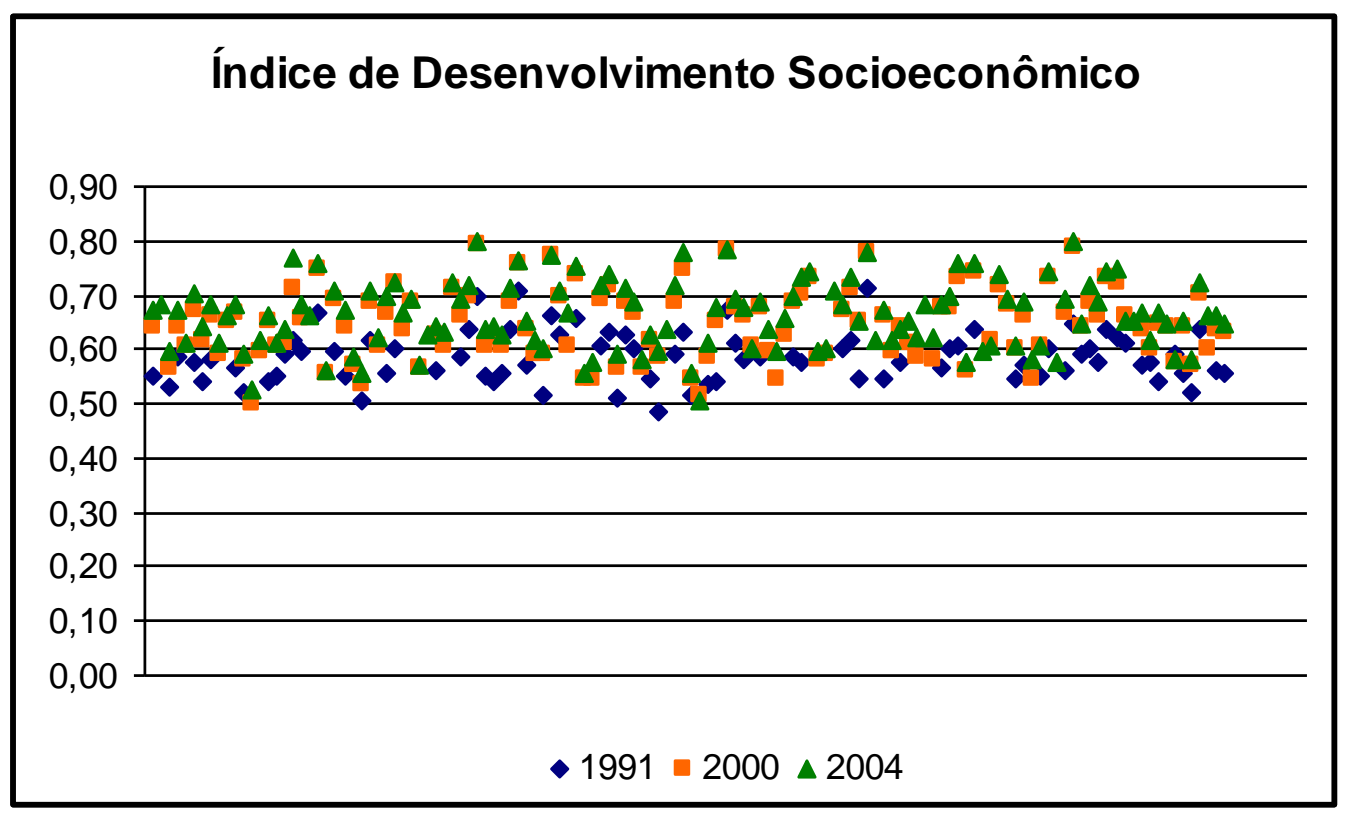

6.8

Indicador

es

de

Infraestru

tura

sistema de

transporte

do Estado

demonstra

um sistema

diversificado, entretanto baseado no transporte rodoviário. A estrutura viária possui ponto de confluência no município de Passo Fundo.

A malha ferroviária presente na RF9 percorre o COREDE Produção e o COREDE Norte. Na região da Produção a malha encontra-se em operação regular para o transporte de cargas, possuindo um ramal com o COREDE Norte, estando desativado o ramal que interliga o município de Erechim no COREDE Norte ao Estado de Santa Catarina e restante do país (GOVERNO DO ESTADO DO RIO GRANDE DO SUL, 2004).

Com relação ao transporte aéreo a RF9 possui um aeroporto na cidade de Passo Fundo, onde realiza conexões diárias com o Estado de São Paulo.

Quanto ao abastecimento de água na RF9, considerados dados do ano de 2000, na zona urbana, 70\% dos domicílios particulares permanentes eram abastecidos por rede geral, e na zona rural o abastecimento era obtido por poço em $24 \%$ dos domicílios. Dados que demonstram a necessidade de ampliação da rede geral de abastecimento de água nos municípios.

$\mathrm{Na}$ zona rural predominaram os domicílios que utilizavam fossa rudimentar para disposição dos resíduos (21,3\%), 4\% dos sanitários eram ligados diretamente a uma vala a céu aberto e 3,2\% dos domicílios particulares permanentes não possuíam banheiro, no ano de 2000. Conforme os percentuais observados, a zona rural necessita de programas e projetos voltados para a construção de sanitários nos domicílios, utilizando o sistema fossa/filtro para a disposição dos resíduos, 
juntamente com a ampliação de programas de habitação rural, para que se garanta melhor qualidade de vida à população que reside nestas áreas.

Na zona urbana, também se observou no ano de 2000, o predomínio dos sanitários ligados à fossa rudimentar em 29,3\% dos domicílios. A rede geral de esgoto atendia 20,3\% dos domicílios particulares permanentes. O percentual de domicílios atendidos por rede geral de esgoto em toda a RF9 assemelha-se com o percentual verificado no município de Passo Fundo, onde a rede de esgoto sanitário não atinge "mais do que 20\% das economias urbanas”, segundo Kalil (2007).

$\mathrm{Na}$ zona rural, em ambos os anos analisados, o lixo era queimado na propriedade, e a segunda forma mais utilizada era enterrado na propriedade. Na zona urbana, no mesmo período, se observou que o destino do lixo era a coleta por empresa pública ou privada realizada em $95 \%$ dos domicílios e a queima no domicílio estava presente em $3 \%$ dos mesmos. O procedimento de queima do lixo como forma de destinação final verificado em municípios da RF9 acarreta danos ao meio ambiente.

A geração de energia elétrica na RF9 tem origem nas grandes hidrelétricas do Rio Uruguai (GOVERNO DO ESTADO DO RIO GRANDE DO SUL, 2004). A região conta, também, com algumas pequenas centrais hidrelétricas (CEEE, 2008). A distribuição de energia elétrica na RF9 no ano de 2005 era realizada pela empresa Rio Grande Energia S.A. (RGE) na maioria dos municípios e apenas nos municípios de Gramado Xavier e Lagoão, ambos pertencentes ao COREDE Alto da Serra do Botucaraí a distribuição era feita pela AES-Sul Distribuidora Gaúcha de Energia S.A.

\subsection{Nível de Hierarquia}

A RF9 possui 90\% dos municípios com nível muito fraco (1) de hierarquia e centralidade. O município de Passo Fundo constitui o polarizador desta região, pois foi classificado com o nível muito forte (7), sendo polarizado apenas pela capital do Estado, Porto Alegre.

Com nível de hierarquia classificada como forte para médio (5) estão os municípios de Erechim, Carazinho e Frederico Westphalen. O município de Palmeira das Missões possui um nível médio (4) de centralidade e os municípios de Getúlio Vargas, Lagoa Vermelha, Marau e Soledade possuíam nível de médio para fraco (3) de hierarquia. Os municípios de Espumoso, Planalto, Sarandi e Tapejara apresentavam nível fraco (2) de centralidade.

\section{CONCLUSÃO}

Com base na caracterização da RF9, foi detectado que a rede urbana é composta por municípios jovens e de pequeno porte, pois dos 130 municípios existentes na região, 65 foram criados no período de 1988-1996. Essas emancipações contribuíram para a formação dos pequenos municípios, nos quais a maioria apresentava população total na faixa de até 5.000 habitantes. 
A perda de população, na maioria dos municípios, foi outro fato observado. Acredita-se que o fenômeno está diretamente relacionado com a carência de oferta de empregos, em que a migração para outras regiões do Estado é uma constante. Contudo, houve um crescimento populacional nos municípios de Marau e Passo Fundo, no período de 2000-2007, em virtude da instalação de novas indústrias nesses municípios, com consequente aumento da oportunidade de emprego e renda, fator atrativo de população.

A maioria dos pequenos municípios que compõem a RF9 não possui uma taxa de urbanização expressiva. Os mesmos se concentram na faixa de 25,01 a 50,00\% de urbanização, possuindo maioria da população total na zona rural. O aumento das taxas de urbanização verificadas ao longo do período analisado se deve aos municípios que apresentam população acima de 20.001 habitantes, os quais possuem de $80 \%$ a $98 \%$ do seu território urbanizado.

$\mathrm{Na}$ saúde, a região apresentou baixas taxas de mortalidade infantil, concentrando a distribuição na faixa de 0,0 a $0,5 \%$. Entretanto, alguns municípios aumentaram suas taxas no período de análise, um deles chegando a 7,6 por mil nascidos vivos, percentual significativo que demonstra que ações de melhoria das condições de qualidade de vida da população se fazem necessárias. Constatou-se, ainda, que a região possui carência no atendimento hospitalar, necessitando a construção de novos leitos e de unidades que ofereçam atendimento básico, evitando o deslocamento da população.

$\mathrm{O}$ atendimento educacional contempla a demanda nos níveis de ensino abordados. Com relação ao Ensino Superior se observou um aumento no acesso, na faixa etária dos 18 aos 24 anos, em virtude da instalação de novas Instituições de Ensino Superior e extensões de IES nesta região a partir do ano de 2004, tanto na forma presencial quanto na modalidade à distância.

A qualidade da educação demonstrou melhora no desempenho dos alunos nos anos iniciais e nos anos finais do Ensino Fundamental, níveis de ensino abordados pela pesquisa, apresentando avaliações positivas e superiores à média nacional. Acredita-se que, a região conseguirá superar a meta estabelecida pelo Ministério da Educação para o ano de 2022, pois os municípios já efetivaram a adesão ao programa federal "Compromisso Todos pela Educação", faltando apenas a execução de todos os itens constantes no Plano de Metas que integra o Plano de Desenvolvimento da Educação.

Com a melhora no desempenho da educação, as taxas de analfabetismo devem apresentar índices menores, apesar da maioria dos municípios estarem na faixa até 10\%. Faz-se importante destacar que $17 \%$ dos municípios apresentaram taxas menores que as estaduais no ano da análise, que era de 6,7. A concentração das taxas nesta faixa de até $10 \%$ estão concentradas na maioria dos municípios dos COREDEs Norte e Produção.

Na RF9, constatou-se uma concentração econômica no COREDE Produção, no qual os Revista Eletrônica: Tempo - Técnica - Território, V.3, N.1 (2012), 152:176 ISSN: 2177-4366 
municípios de Passo Fundo, Carazinho e Marau possuem as maiores concentrações do PIB, podendo ser incluído o município de Erechim, pertencente ao COREDE Norte e apresentando o segundo maior PIB da RF9.

O desempenho econômico positivo verificado no período e o baixo crescimento populacional contribuiram para o aumento do PIB per capita na RF9, na qual os maiores valores observados foram detectados nos municípios com maior participação no VAB industrial, Aratiba e Marau.

A estrutura produtiva verificada na atividade de serviço se deve ao fato dos maiores percentuais estarem concentrados nos municípios com maior PIB, dentre eles: Passo Fundo, Erechim, Carazinho, Palmeira das Missões, Frederico Westphalen, Lagoa Vermelha e Soledade.

Foi verificada na rede urbana da RF9 a deficiência na malha viária, dificultando a relação intra-urbana entre os municípios e a possibilidade de atrair investimentos, especialmente nos acessos às sedes municipais que não apresentam pavimentação. Fato que merece implementação de ações de melhorias na infraestrutura viária para permitir a integração regional.

Outra medida que se apresenta necessária é o aumento da rede de abastecimento de água na zona urbana e rural, tendo em vista os dados levantados no estudo de caso, no qual os municípios não possuem a totalidade da sua população atendida. Prioritariamente, se deve implantar rede de coleta de esgoto na zona urbana, juntamente com estações de tratamento para proporcionar melhores condições sanitárias à população, procurando evitar a disseminação de doenças e elevar os índices de desenvolvimento relacionado com esse indicador.

$\mathrm{Na}$ zona rural, o sistema fossa séptica/filtro anaeróbio deveria ser incorporado como forma de esgotamento sanitário, pois com a pesquisa observou-se que a forma utilizada na maioria dos domicílios rurais é a fossa rudimentar, fator que pode ocasionar contaminação do lençol freático.

Na RF9, a coleta de lixo por empresa pública ou privada na zona urbana foi observada na maioria dos municípios. Contudo, na zona rural a queima de lixo na propriedade chamou a atenção por estar no cotidiano da população. Essa forma de disposição dos resíduos acredita-se estar atrelada à falta de periodicidade na coleta nesta zona. Para minimizar essa forma utilizada pela população rural e também verificada em muitos municípios na zona urbana, um programa de coleta seletiva deveria ser efetivado, juntamente com o aumento da periodicidade da coleta por empresa pública ou privada. A rede urbana da RF9 possui municípios com nível muito fraco de hierarquia e centralidade, demonstrando a carência de oferta de serviços especializados à população.

Portanto, a rede urbana da RF9 apresenta muitos desafios a serem enfrentados para que eleve o nível de desenvolvimento, um dos principais é a deficiência na infraestrutura viária que vem comprometer futuros investimentos empresarias nessa região. Dessa forma, faz-se necessária a implementação de melhorias na malha viária regional. Também, se observa a necessidade de 
implementar programas de gestão ambiental, bem como incentivo na diversificação agrícola e na produção agroindustrial de pequenos produtores. Consequentemente, a região poderia aumentar o seu nível competitivo no cenário estadual e nacional e conseguiria atingir um desenvolvimento sustentável.

\section{REFERÊNCIAS BIBLIOGRÁFICAS}

ALONSO, J. A. F. O cenário regional gaúcho nos anos 90: convergência ou mais desigualdade? Indicadores Econômicos FEE, Porto Alegre, v. 31, n. 3, p. 97-118, nov. 2003.

ALONSO, J. A. F.; AMARAL, R. Q. Desigualdades intermunicipais de renda no Rio Grande do Sul: 1985-2001. Ensaios FEE, v. 26, p. 171-194, 2005.

BANDEIRA, P. S. Participação, articulação de atores sociais e desenvolvimento regional. In: BECKER, D. F.; BANDEIRA, P. S. (Org.). Determinantes e Desafios Contemporâneos. Vol. 1. Santa Cruz do Sul: EDUNISC, 2000, p. 23-128.

BARROS, V. L. M. Povoamento e urbanização do Rio Grande do Sul. In: WEIMER, G. (Org.) Urbanismo no Rio Grande do Sul. Porto Alegre: Ed. Universidade UFRGS, 1992. p. 35-55.

CASTELLS, M. A sociedade em rede. 9.ed. São Paulo: Paz e Terra, 1999.

CORRÊA, R. L. Uma nota sobre o urbano e a escala. Revista Território, Rio de Janeiro, ano VII, n.11, 12 e 13, p.133-136, 2003.

Estudos sobre a rede urbana. Rio de Janeiro: Bertrand Brasil, 2006.

FONSECA, A. A. M.; O’NEILL, M.M. A revolução tecnológica e informacional e o renascimento das redes. Revista de Geociências, Niterói, RJ, v. 2, p. 26-35, 2001.

FUNDAÇÃO DE ECONOMIA E ESTATÍSTICA. Obtenção de dados. Disponível em:< http://www.fee.rs.gov.br/feedados/consulta/sel_modulo_pesquisa.asp> Acesso em: abr. 2008.

GOVERNO DO ESTADO DO RIO GRANDE DO SUL. Relatório Síntese do Estudo RumoS 2015. Porto Alegre, 2004.

HAESBAERT, R. 0 mito da desterritorialização do “fim dos territórios" à multiterritorialidade. 2. ed. Rio de Janeiro: Berthand Brasil, 2006. 400p.

HAFFNER, J. A. H. A Economia Gaúcha diante do cenário macroeconomico nacional e regional. In: Terceiro Encontro de Economia Gaúcha, 2006, Anais..., Porto Alegre, 2006. v. 1. p. 1-15.

INEP. Consulta ao Índice de Desenvolvimento da Educação. Disponível em: <http://ideb.inep.gov.br/site/> Acesso em: nov. 2008.

Busca de instituição de Ensino Superior. Disponível em: <http: www.educacaosuperior.inep.gov.br/inst_municipio.asp> Acesso em: jan. 2009.

INSTITUTO BRASILEIRO DE GEOGRAFIA E ESTATÍSTICA. Contagem da população 2007. Disponível em: <http://www.ibge.gov.br> Acesso em: 23 nov. 2007.

INSTITUTO DE PESQUISA ECONÔMICA APLICADA - IPEA, IBGE, UNICAMP. Caracterização e tendências da rede urbana do Brasil. Brasília: IPEA, 2000.

Estudos básicos para a caracterização da rede urbana. Brasília: IPEA, 2002.

JARDIM, M. L.; BARCELLOS, T. M. Os movimentos populacionais no Rio Grande do Sul: uma visão inter e intra-regional através dos Coredes. Ensaios FEE, Porto Alegre, v. 26, Número Especial, p. 143-170, maio 2005. 
KALIL, R. Redes de Infra-estrutura urbana: gestão de programas e projetos na cidade de Passo Fundo de 2005 a 2007. 2007. Dissertação (Mestrado em Engenharia) - Faculdade de Engenharia e Arquitetura, Universidade de Passo Fundo, Passo Fundo, 2007.

MOREIRA, I. O espaço rio-grandense. 4 ed. São Paulo: Ática: 2000.

RAMBO, A. G. ; CAZAROTTO, R. T. . Redes, Territórios e o Desenvolvimento Territorial Local/Regional. In: XXVIII Encontro Estadual de Geografia, 2008, Bento Gonçalves. Anais do XXVIII Encontro Estadual de Geografia. Bento Gonçalves : UCS, 2008.

RANGEL, S. S. et. al. Distribuição espacial dos municípios emergentes do processo emancipatório. Evolução da territorialidade municipal. Algumas considerações. Boletim Gaúcho de Geografia, Porto Alegre, n. 23, p.41-51, mar. 1998.

RIO GRANDE DO SUL. Decreto No 35.764, de 28 de dezembro de 1994. Regulamenta a Lei $N^{\circ}$ 10.283, de 17 de outubro de 1994, que criou os Conselhos Regionais de Desenvolvimento - CRDs. Disponível em: 〈http://www.al.rs.gov.br/legis/>. Acesso: abr. 2008.

SANTOS, M. A natureza do espaço: técnica e tempo, razão e emoção. São Paulo: EDUSP, 2002. 